\title{
Michele Sarfatti
}

Die Juden im faschistischen Italien

Judaica

Band 4 


\title{
Juristische Zeitgeschichte
}

Herausgegeben von

Prof. Dr. Dr. Thomas Vormbaum (FernUniversität in Hagen)

\author{
Abteilung 8: \\ Judaica - \\ Jüdisches Recht, Judenrecht, Recht und Antisemitismus \\ Herausgegeben von Prof. Dr. Dr. Thomas Vormbaum
}

Band 4

Redaktion: Zekai Dağaşan 
Michele Sarfatti

\section{Die Juden im faschistischen Italien}

Geschichte, Identität, Verfolgung

Aus dem Italienischen

von

Thomas Vormbaum

und Loredana Melissari

De Gruyter 
Michele Sarfatti ist Historiker und Leiter des Dokumentationszentrums jüdischer Zeitgeschichte (Centro di Documentazione Ebraica Contemporanea) in Mailand.

Gedruckt mit finanzieller Unterstützung des Zentralrats der Juden in Deutschland

ISBN 978-3-11-036768-3

e-ISBN 978-3-11-034610-7

Bibliografische Information der Deutschen Nationalbibliothek

Die Deutsche Nationalbibliothek verzeichnet diese Publikation in der Deutschen Nationalbibliografie; detaillierte bibliografische Daten sind im Internet über http://dnb.d-nb.de abrufbar.

(C) 2014 Walter de Gruyter GmbH, Berlin/Boston

Druck: Hubert \& Co. GmbH \& Co. KG, Göttingen

$\circledast$ Gedruckt auf säurefreiem Papier

Printed in Germany

www.degruyter.com 